\title{
Solubility of imidazolium-based ionic liquids in model fuel hydrocarbons: A COSMO-RS and experimental study
}

Zhen Song, Qian Zeng, Jinwei Zhang, Hongye Cheng, Lifang Chen, and Zhiwen Qi ${ }^{*}$

Max Planck Partner Group at the State Key Laboratory of Chemical Engineering, School of Chemical Engineering, East China University of Science and Technology,

Shanghai 200237, China

*Corresponding author: zwqi@ecust.edu.cn

\begin{abstract}
When applying ionic liquids (ILs) in extractive and oxidative desulfurization of fuel oils, the potential solubility of IL in fuel phase is an important concern whereas research particularly on this issue is still scarce. In this work, COSMO-RS was first employed to predict the solubilities of 220 imidazolium-based ILs (11 cations and 20 anions) in 7 model fuel hydrocarbons (namely, $n$-hexane, $n$-heptane, $n$-octane, $i$-octane, cyclohexane, benzene and toluene), which cover different characters of ILs and hydrocarbons. To understand the effect of IL and hydrocarbon on the IL-in-hydrocarbon solubility, different types of molecular interactions between IL and hydrocarbon were further analyzed from COSMO-RS point of view. Finally, the solubilities of 5 representative ILs in the studied hydrocarbons were experimentally determined by nitrogen analyzer, demonstrating the good qualitative and acceptable quantitative ability of COSMO-RS for predicting IL-in-hydrocarbon solubilities.
\end{abstract}

Keywords: ionic liquid solubility; fuel hydrocarbon; COSMO-RS; molecular interactions; solubility experiment 


\section{Introduction}

In recent years ionic liquids (ILs) have attracted increasing interest as alternatives of volatile organic solvents in different reaction or separation systems due to their unique physicochemical properties, such as non-volatility, high thermal/chemical stability, wide liquid range, easy tunable character, and so on [1-6]. Among the various explorations, several fuel-related processes using ILs as solvent, especially extractive desulfurization (EDS) and oxidative desulfurization (ODS) of fuel oils, are extensively studied [7-12].

Compared with the conventional hydrodesulfurization (HDS) approach, EDS and ODS have the advantages of mild process conditions, facile operation options and high selectivity towards aromatic sulfur compounds, etc. Particularly for ODS, with the introduction of a small amount of oxidant and in some cases also catalyst, the aromatic sulfur compounds can be oxidized to their corresponding sulfoxides or sulfones, which significantly increase the solubility of sulfur compounds in ILs and thus promote the desulfurization efficiency [10-12]. Moreover, the huge number of possible ILs offers a great space for the selection or design of solvent to further improve the desulfurization efficiency. Therefore, EDS and ODS are expected to be highly promising alternatives or complements to the HDS process for deep desulfurization in the future, and many researchers are striving to search more suitable ILs over a broader range [13-17].

So far, in the EDS and ODS contributions with IL solvent, the desulfurization performance of IL is intensively concerned while the potential solubility of IL in fuel oil is scarcely taken into account [10-12]. Commonly, it is assumed that the amount of ILs dissolved in the raffinate fuel phase is negligible. However, such assumption cannot be widely acceptable since the existence of ILs in the raffinate of desulfurization or 
other similar systems has already been observed experimentally [5,16-18]. For instance, in the EDS study of Lu et al., the mass ratio of [ $\left.\mathrm{C}_{1} \mathrm{pi}\right][\mathrm{Lac}],\left[\mathrm{C}_{2} \mathrm{pi}\right][\mathrm{Lac}]$ and $[\mathrm{TMG}][\mathrm{Lac}]$ in the raffinate phase was determined to be $0.53 \mathrm{wt} \%, 0.88 \mathrm{wt} \%$ and $0.1 \mathrm{wt} \%$ by ${ }^{1} \mathrm{H}-\mathrm{NMR}$ spectroscopy [16]. Moreover, as the raffinate of desulfurization systems is mainly composed of aliphatic and aromatic hydrocarbons, the solubility of IL in fuel oil can also be evaluated through the solubility of IL in such model fuel hydrocarbons. Domańska et al. carried out several studies on the phase equilibria of $\{\mathrm{IL}+$ aromatic/aliphatic hydrocarbons \}, which validate the presence of ILs in hydrocarbons (particularly in aromatic hydrocarbons) [19-25]. Similar experimental observations were also found by other researchers [26-29]. All these studies indicate the potential solubility of ILs in fuel oil.

For IL-based EDS and ODS processes, even a slight solubility of ILs in fuel may lead to serious subsequent problems concerning the following aspects: (a) If ILs are entrained into the fuel phase, the nitrogen or sulfur content will be enhanced since ILs are mostly nitrogen-containing and/or sulfur-containing. This is strongly undesired as these processes are mainly focused on removing the last trace of sulfur compounds in fuel oils (e.g. to below $10 \mathrm{ppm}$ ); (b) To make matters worse, the composition and quality of fuels may dramatically deteriorate because of the complex properties of the dissolved ILs; (c) Recycling the dissolved IL from the fuel phase is challenging and will also increase the overall separation cost.

Considering the above facts, Song et al. combined the solubility of IL in the raffinate phase with the extractive capacity and selectivity to screen ILs for EDS process. Through COSMO-RS prediction and experimental validation, the negligible solubility and competitive desulfurization performance of $\left[\mathrm{C}_{4} \mathrm{mim}\right]\left[\mathrm{H}_{2} \mathrm{PO}_{4}\right]$ were demonstrated [30]. Very recently, Gao et al. evaluated the mutual solubility of ILs and 
fuel oils (simulated with DBT and $n$-octane) by COSMO-RS, and verified by experiments with 5 different ILs [31]. However, up to now, the ILs that have been covered can only account for a very small proportion of the large number of possible ILs, and the available experimental data on the solubility of IL in fuel oils are still very scarce.

In this contribution, the solubility of IL in fuel hydrocarbon was particularly investigated combining COSMO-RS and experiment. The solubilities of 220 imidazolium-based ILs in 7 model fuel hydrocarbons were first predicted by COSMO-RS, thereby suggesting the effect of IL and hydrocarbon characters on the IL-in-hydrocarbon solubility. COSMO-RS based analysis of the molecular interactions in the IL-in-hydrocarbon systems was then performed to understand the effect of IL and hydrocarbon as well as the intrinsic solubility behavior. Moreover, to validate the COSMO-RS predictions, the solubilities of 5 representative ILs in the studied hydrocarbons were experimentally determined.

\section{Method description}

\subsection{COSMO-RS prediction and analysis}

Since an elaborate description of the conductor-like screening model for real solvents (COSMO-RS) can be found elsewhere [32,33], only the major features for understanding the prediction and analysis in the work were briefly addressed as follows.

A standard COSMO-RS calculation only requires the screening charge density (also known as $\sigma$-profile) of the interested compounds, which details the amount of surface segment type with a certain polarity interval. The properties of liquid or liquid 
mixtures can be calculated based on interacting molecular surfaces combining the $\sigma$-profile with a fast and accurate statistical thermodynamic treatment [32]. The current COSMO database already contains the $\sigma$-profiles of thousands of conventional solvents and most of the reported cations and anions of ILs. In this work, all the $\sigma$-profiles of involved cations and anions of ILs, as well as the hydrocarbons were taken from the standard database of the COSMOthermX (Version C30_1401). The BP_TZVP_C30_1401 parameterization in the software was employed for the COSMO-RS calculations.

The molar-based solubility of an arbitrary solute $i$ in any pure or mixed solvent $\left(x_{i}\right)$ is calculated by

$$
\log _{10}\left(x_{i}\right)=\left(\mu_{i}^{\text {pure }}-\mu_{i}^{\text {solvent }}-\Delta G_{i, \text { fusion }}\right) / R T \ln 10
$$

where $\mu_{i}^{\text {pure }}$ and $\mu_{i}^{\text {solvent }}$ represent the chemical potential of the solute $i$ in the pure solute and in the solvent, respectively, and $\Delta G_{i, \text { fusion }}$ is the Gibbs free energy of fusion. $\Delta G_{i, f u s i o n}$ is zero for liquid solutes and has to be given or estimated for solid compounds. The thus calculated solubility is a zeroth order approximation, which is only valid for small concentrations of the solute. To improve the accuracy of prediction, $x_{i}$ can be refined iteratively into the solubility calculation as expressed by

$$
\log _{10}\left(x_{i}^{(n+1)}\right)=\left(\mu_{i}^{\text {pure }}-\mu_{i}^{\text {solvent. }(n)}-\Delta G_{i, \text { fusion }}\right) / R T \ln 10
$$

This procedure can be repeated until the differences in the computed value of $x_{i}$ are below a certain threshold.

In the COSMO-RS theory, three intermolecular interaction parameters, namely the misfit energy, the HB energy and the vdW energy, can be derived to quantify the electrostatic interactions, the hydrogen bonding interactions and the van der Waals 
interactions, respectively. Thereby, the macroscopic thermodynamic properties (e.g., solubility) can be attributed to the most important molecular interaction forces through the determination of different types of molecular interaction energies based on COSMO-RS computation [32-34].

\subsection{Experimental}

The model fuel hydrocarbons, i.e., $n$-hexane, $n$-heptane, $n$-octane, $i$-octane, cyclohexane, benzene and toluene were purchased from Aladdin Chemical Co., Ltd., and the purity, density, etc. of these chemicals were tabulated in Table S1 (Supporting Information). The ILs $\left[\mathrm{C}_{4} \mathrm{mim}\right]\left[\mathrm{HSO}_{4}\right],\left[\mathrm{C}_{\mathrm{n}} \mathrm{mim}\right][\mathrm{OAc}](\mathrm{n}=4,6,8)$ and $\left[\mathrm{C}_{4} \mathrm{mim}\right][\mathrm{DBP}]$ were supplied by Lanzhou Institute of Chemical Physics, Chinese Academy of Sciences with purity higher than $98.5 \mathrm{wt} \%$, which was verified by ${ }^{1} \mathrm{H}-\mathrm{NMR}$ characterization. Before use, the ILs were dried for $48 \mathrm{~h}$ under reduced pressure to remove possible volatile impurities and traces of water (EYELA N-1100, Japan). After drying, the water content in the ILs was determined to be below 1000 ppm with an AQV-300 Karl-Fischer volumetric titration (Hiranuma, Japan). The detailed information about the ILs was provided in Table S2 (Supporting Information).

The experiment of IL solubility in hydrocarbon or hydrocarbon mixtures was performed at $298.15 \mathrm{~K}$ and atmospheric pressure. In a typical run, a specific amount of IL and hydrocarbon were successively introduced into a screw-capped vial, where the mass of each component was measured gravimetrically by a Sartorius BSA224S-CW balance (Germany) with a precision of $\pm 0.0001 \mathrm{~g}$. After tightly sealed, the mixture was continuously agitated with a magnetic stirrer for $3 \mathrm{~h}$ and then left to settle for $6 \mathrm{~h}$ to ensure complete thermodynamic equilibrium. The liquid temperature was controlled by an oil bath with a temperature fluctuation of $\pm 0.1 \mathrm{~K}$ (Huber Ministat 230, Germany). After settling, the sample of the upper hydrocarbon phase was carefully withdrawn. 
Since imidazolium-based ILs are nitrogen-containing, the IL-in-hydrocarbon solubility can then be determined by the increase in the nitrogen content before and after IL was dissolved ( $\Delta N$-content) by a chemiluminescence nitrogen analyzer (Antek 9000, USA) $[17,18]$. The measuring range of the nitrogen analyzer is $20 \mathrm{ppb}$ to 0.17 , and different calibration lines can be adopted at each small interval within the range to ensure the accuracy of measurements. The analysis of each sample was repeated for three times and the relative standard deviation of different injections was estimated to be within \pm 0.02 . To ensure the reproducibility of the results, the involved experiments were carried out in triplicate and the average was finally presented. The uncertainties of the determined IL-in-hydrocarbon solubility were estimated to be less than \pm 0.03 (Table 1).

\section{Results and discussion}

\subsection{Validation of COSMO-RS predictions}

As summarized by Ferreira et al., it is challenging to measure the very low solubility of ILs in hydrocarbons by conventional approaches (e.g., visual cloud point detection and volumetric method) and there may be some discrepancies for similar systems by different experimental techniques $[35,36]$. Nevertheless, the experimentally determined IL-in-hydrocarbon solubility data in previous literature [23-30] were reviewed to preliminarily evaluate the reliability of COSMO-RS predictions here. The available ILs are mainly imidazolium-based but also cover other cationic categories, like pyridinium and phosphonium. Their anions are of a number of different types, i.e., $\left[\mathrm{BF}_{4}\right]^{-},\left[\mathrm{EtSO}_{4}\right]^{-},[\mathrm{Tos}]^{-},[\mathrm{SCN}]^{-},[\mathrm{OTf}]^{-},[\mathrm{OAc}]^{-},\left[\mathrm{Tf}_{2} \mathrm{~N}\right]^{-},\left[\mathrm{H}_{2} \mathrm{PO}_{4}\right]^{-},\left[\mathrm{NO}_{3}\right]^{-}$.

The experimental and predicted solubilities of these ILs in different hydrocarbons were compared together (Table S3, Supporting Information). As seen in Fig. 1a, despite 
some reasonable deviations, the COSMO-RS predicted IL solubilities are in good qualitative agreement with the experimental results, which can be identified by the relatively high correlation $\left(\mathrm{R}^{2}=0.8238\right)$. In addition, the quantitative prediction performance of COSMO-RS was estimated through the absolute average relative deviation (AARD), which is calculated by

$$
\mathrm{AARD}=\frac{1}{n} \sum_{t=1}^{n}\left|\frac{\log _{10} x^{\mathrm{exp}}-\log _{10} x^{\mathrm{cal}}}{\log _{10} x^{\exp }}\right|
$$

where $\log _{10} x^{\exp }$ and $\log _{10} x^{\text {cal }}$ represent the experimental and predicted IL-in-hydrocarbon solubility, respectively. The AARD of all the available IL-in-hydrocarbon systems is 0.1489 . Considering the fully predictive character of COSMO-RS, these predictions are quantitatively acceptable. Moreover, as shown in Fig. $1 \mathrm{~b}$, the tendency of $\left[\mathrm{C}_{6} \mathrm{mim}\right]\left[\mathrm{NO}_{3}\right]$ solubility in different hydrocarbons (even in isomers, i.e., $o$-xylene, $m$-xylene, $p$-xylene) can also be reasonably distinguished in spite of a certain quantitative deviation [29]. Besides, it has been proved that COSMO-RS could provide a right qualitative and in many cases also quantitative description of the phase behaviors of the $\{\mathrm{IL}+$ aromatic / aliphatic hydrocarbon $\}$ systems [35,36]. Therefore, COSMO-RS is a promising tool for predicting the solubilities of ILs in different hydrocarbons.

\subsection{COSMO-RS predicted IL-in-hydrocarbon solubility}

The solubilities of 220 ILs (combined by 11 cations and 20 anions) in 7 hydrocarbons (namely, $n$-hexane, $n$-heptane, $n$-octane, $i$-octane, cyclohexane, benzene and toluene) were calculated by COSMO-RS. These hydrocarbons cover various characters (including alkanes, cycloalkanes and aromatics) and are typical model fuel components in literature [10-17]. The detailed information of the investigated cations and anions was given in Table S4 (Supporting Information). Due to the facile 
accessibility, easy tunability and high stability, only the imidazolium-based ILs were concentrated on. Consequently, the cations $\left(\left[\mathrm{C}_{1} \mathrm{im}\right]^{+},\left[\mathrm{C}_{\mathrm{n}} \mathrm{mim}\right]^{+}\right.$and $\left.\left[\mathrm{C}_{4} \mathrm{mmim}\right]^{+}\right)$which cover different cationic characters, i.e., alkyl substituent number and alkyl chain length, were involved. The selected anions included the most widely used ones (e.g., $\left[\mathrm{BF}_{4}\right]^{-}$, $\left.\left[\mathrm{PF}_{6}\right]^{-},\left[\mathrm{TF}_{2} \mathrm{~N}\right]^{-}\right)$and other typical categories, such as -phosphate, -sulfate and -sulfonate.

The COSMO-RS predicted results were depicted in Figs. 2 and S1, and listed in Table S5 (Supporting Information). To provide a clear comparison of the effect of cation and anion, the cations were arranged in the order of increasing alkyl substituent number or alkyl chain length, and the anions were ranked in the order of enhancing solubility in $n$-hexane for their combinations with $\left[\mathrm{C}_{4} \mathrm{im}\right]^{+}$. As illustrated, although the IL solubility in $n$-hexane (Fig. 2a) is 2 - 3 logarithmic units lower than that in benzene (Fig. 2b), a very similar pattern can be observed for the solubilities of ILs in these two hydrocarbons. This is also the case for the solubilities of ILs in the other studied hydrocarbons (Fig. S1, Supporting Information). These facts demonstrate that the solubilities of ILs in different hydrocarbons present an analogous dependency on the IL structure (i.e., cation-anion combination), which is generally independent of the hydrocarbon character. The effect of cation and anion character on the IL-in-hydrocarbon solubility can be evaluated from its change in the $y$ direction and $x$ direction, respectively. As can be seen, both cation and anion have a considerable effect on the IL-in-hydrocarbon solubility. For example, for each anion, the solubilities of its combinations with different cations generally increase along the $y$ direction, indicating that more alkyl substituent or longer alkyl chain on the cation will result in higher IL solubility. With a fixed cation, the solubilities of the ILs paired with different anions 
notably increase along the $x$ direction, which means that ILs with the anions on the right side tend to be more soluble in hydrocarbons.

The effect of hydrocarbon character on the IL-in-hydrocarbon solubility, i.e., the solubility of IL in different hydrocarbons was compared with the ILs $\left[\mathrm{C}_{\mathrm{n}} \mathrm{mim}\right][\mathrm{OAc}]$ $(n=1-10)$ as example (Fig. 3). For all these ILs, their solubilities in different hydrocarbons generally follow the order of $n$-hexane $<n$-heptane $<n$-octane $<i$-octane $<$ cyclohexane < toluene < benzene, where the solubility of ILs in aromatic hydrocarbons are 2 - 3 logarithmic units higher than that in aliphatic hydrocarbons. Although the solubilities of ILs in $n$-alkanes are very close, they slightly increase with longer alkane chain. For instance, the logarithmic solubilities of $\left[\mathrm{C}_{4} \mathrm{mim}\right][\mathrm{OAc}]$ in $n$-hexane, $n$-heptane, $n$-octane are $-5.869,-5.856$ and -5.835 , respectively. Such an effect of $n$-alkane chain length on the IL-in-hydrocarbon solubility is different from that on the hydrocarbon-in-IL solubility, where $n$-alkane with shorter chain length is more soluble in ILs [35]. This indicates different solvation mechanisms for the dissolution of IL in $n$-alkane and the dissolution of $n$-alkane in IL, respectively. The cases of $n$-octane and $i$-octane demonstrate that isomerized alkanes are favorable for dissolving ILs (e.g., the $\left[\mathrm{C}_{2} \mathrm{mim}\right][\mathrm{OAc}]$ solubilities in $n$-octane and in $i$-octane are -6.102 and -5.993 , respectively). Similarly, the higher IL solubility in cycloalkane than in the corresponding $n$-alkane is also observed. The solubilities of other types of ILs in these hydrocarbons show consistent tendencies as that of $\left[\mathrm{C}_{\mathrm{n}} \mathrm{mim}\right][\mathrm{OAc}]$ (Table $\mathrm{S} 5$, Supporting Information).

\subsection{COSMO-RS based analysis of molecular interactions}

To interpret the effect of IL and hydrocarbon characters on the IL-in-hydrocarbon solubility and further understand the intrinsic solubility behavior, different types of molecular interactions in the case of IL dissolving in hydrocarbon were analyzed by 
COSMO-RS computation (Table S6, Supporting Information). Due to the strong non-polarity of the hydrocarbons, the HB interactions between IL and hydrocarbons are negligible and the solute-solvent interactions in these IL-in-hydrocarbon systems mainly exist in terms of $\mathrm{vdW}$ and misfit energies. The negative vdW interactions demonstrate that they are favorable for the dissolution of IL in hydrocarbon; while the positive misfit interactions are disadvantageous since they indicate mismatching property and contradictive interactions between IL and hydrocarbon $[32,37,38]$.

Considering the effects of cation and anion on the IL solubility in different hydrocarbons are similar, only the molecular interactions in the cases of [OAc]-based and $\left[\mathrm{C}_{4} \mathrm{mim}\right]$-based ILs dissolving in $n$-hexane are discussed as illustration. As seen in Fig. 4a, when $[\mathrm{OAc}]^{-}$is paired with $\left[\mathrm{C}_{4} \mathrm{im}\right]^{+},\left[\mathrm{C}_{4} \mathrm{mim}\right]^{+}$and $\left[\mathrm{C}_{4} \mathrm{mmim}\right]^{+}$, respectively, the vdW interactions between IL and $n$-hexane gradually increase from $-9.064 \mathrm{kcal} / \mathrm{mol}$, $-10.143 \mathrm{kcal} / \mathrm{mol}$ to $-10.821 \mathrm{kcal} / \mathrm{mol}$; on the other side, the corresponding misfit interactions decrease remarkably ( $5.414 \mathrm{kcal} / \mathrm{mol}, 4,134 \mathrm{kcal} / \mathrm{mol}, 3.694 \mathrm{kcal} / \mathrm{mol})$. Both the changes in these two aspects are favorable for the dissolution of IL and thus the increasing IL solubility with more cation alkyl substituent can be well understood. The effect of cation alkyl chain length on the IL solubility can be interpreted in a similar manner. With longer alkyl chain, the misfit energies first slightly decrease from 4.442 $\mathrm{kcal} / \mathrm{mol}\left(\left[\mathrm{C}_{1} \mathrm{mim}\right]^{+}\right)$to $4.147 \mathrm{kcal} / \mathrm{mol}\left(\left[\mathrm{C}_{3} \mathrm{mim}\right]^{+}\right)$, and then keep nearly constant with further lengthening the alkyl chain to $\left[\mathrm{C}_{10} \mathrm{mim}\right]^{+}$; meanwhile, the vdW interactions almost increase linearly from $-7.212 \mathrm{kcal} / \mathrm{mol}$ of $\left[\mathrm{C}_{1} \mathrm{mim}\right]^{+}$to $-16.143 \mathrm{kcal} / \mathrm{mol}$ of $\left[\mathrm{C}_{10} \mathrm{mim}\right]^{+}$. The combined effect of vdW interactions and misfit energies will also lead to the higher solubilities of ILs with longer alkyl chains.

Figure $4 \mathrm{~b}$ present the analysis of molecular interactions for the dissolution of $\left[\mathrm{C}_{4} \mathrm{mim}\right]$-based ILs with different anions in $n$-hexane. As illustrated, both the misfit 
interactions and vdW interactions show some fluctuations as the anion changes along the $x$ direction. But the misfit energies basically exhibit a gradual decreasing tendency, which reasonably agrees with the increasing trend of IL solubility. Moreover, it can be found that the wave crests of the misfit energies almost correspond one by one to the wave troughs of the vdW energies. It suggests that the anions with relatively higher misfit energies along the decreasing trend can be compensated by the relatively stronger vdW interactions, which jointly contribute to the tendency of increasing IL solubility on the $x$ direction. Therefore, the effect of anion on the IL solubility can also be attributed to the misfit interactions and vdW interactions, where the former plays a primary role and the latter plays a secondary role.

To understand the effect of hydrocarbon character on the IL-in-hydrocarbon solubility, the molecular interactions in the cases of $\left[\mathrm{C}_{4} \mathrm{mim}\right][\mathrm{OAc}]$ dissolving in different hydrocarbons are addressed as example. As seen in Fig. 5, the vdW interactions between $\left[\mathrm{C}_{4} \mathrm{mim}\right][\mathrm{OAc}]$ and different hydrocarbons are in a very close range from $-14.059 \mathrm{kcal} / \mathrm{mol}$ ( $i$-octane) to $-14.154 \mathrm{kcal} / \mathrm{mol}$ (benzene), which indicate a trivial influence of hydrocarbon character on the IL-hydrocarbon vdW interactions. With increasing the alkane chain length from $n$-hexane to $n$-octane, the vdW interactions present a slight decreasing tendency, which is unfavorable for the dissolution of IL; on the contrary, the misfit energies between IL and hydrocarbon gradually decrease from $14.569 \mathrm{kcal} / \mathrm{mol}$ to $14.544 \mathrm{kcal} / \mathrm{mol}$, suggesting a beneficial decline in the contradictive interactions between $\left[\mathrm{C}_{4} \mathrm{mim}\right][\mathrm{OAc}]$ and the hydrocarbons. Combining these two aspects, the higher solubility of IL in longer $n$-alkanes is mainly dominated by the change in misfit energies. Similarly, the effect of the isomerization or cyclization of alkane on the IL-in-hydrocarbon solubility can also be understood by the decrease in the misfit energies in these systems. In the cases of benzene and toluene, the 
misfit energies between IL and hydrocarbon are lower while the vdW interactions are higher than those in the other hydrocarbons, which both favorably promote the IL solubility.

The analysis of molecular interactions in the other systems (Table S6, Supporting Information) generally concurs with the above conclusions. Overall, both the effect of IL (cation and anion) and hydrocarbon characters on the IL-in-hydrocarbon solubility can be reasonably understood from the molecular interactions point of view.

\subsection{Experimental IL-in-hydrocarbon solubility}

Although the effect of IL structure on the IL-in-hydrocarbon solubility can be roughly validated by the data of $\left[\mathrm{C}_{6} \mathrm{mim}\right]\left[\mathrm{NO}_{3}\right],\left[\mathrm{C}_{8} \mathrm{mim}\right]\left[\mathrm{NO}_{3}\right],\left[\mathrm{C}_{4} \mathrm{mim}\right]\left[\mathrm{BF}_{4}\right]$, $\left[\mathrm{C}_{4} \mathrm{MIM}\right][\mathrm{SCN}]$ and $\left[\mathrm{C}_{4} \mathrm{mim}\right]\left[\mathrm{H}_{2} \mathrm{PO}_{4}\right][25,26,29,30]$, a systematic experimental comparison is still lacking since these data were obtained either under different conditions or in different hydrocarbons. Therefore, in this section, the solubilities of 5 representative ILs (namely $\left[\mathrm{C}_{4} \mathrm{MIM}\right]\left[\mathrm{HSO}_{4}\right], \quad\left[\mathrm{C}_{4} \mathrm{MIM}\right][\mathrm{OAc}], \quad\left[\mathrm{C}_{6} \mathrm{MIM}\right][\mathrm{OAc}]$, $\left[\mathrm{C}_{8} \mathrm{MIM}\right][\mathrm{OAc}]$ and $\left.\left[\mathrm{C}_{4} \mathrm{MIM}\right][\mathrm{DBP}]\right)$ in the 7 studied hydrocarbons were experimentally determined at $298.15 \mathrm{~K}$ to further verify the COSMO-RS predictions. The selected ILs cover different characteristics of anion or cation alkyl chain length, which could provide a direct comparison of the effect of IL structure suggested by COSMO-RS. Moreover, all these ILs have already been reported in EDS and/or ODS applications $[17,39,40]$ and are available from commercial IL suppliers.

The experimental results were listed in Table 1 and depicted in Fig. 6. As seen, for all the hydrocarbons, the solubilities of $\left[\mathrm{C}_{\mathrm{n}} \mathrm{mim}\right][\mathrm{OAc}]$ in them can be ranked as $\left[\mathrm{C}_{8} \mathrm{mim}\right][\mathrm{OAc}]>\left[\mathrm{C}_{6} \mathrm{mim}\right][\mathrm{OAc}]>\left[\mathrm{C}_{4} \mathrm{mim}\right][\mathrm{OAc}]$. For instance, the solubilities of these ILs in benzene are $-2.811,-3.128$ and -3.716 in logarithmic units, respectively. 
Thus, the COSMO-RS prediction that ILs with longer alkyl chain are more soluble in hydrocarbon is well verified. Similarly, the ranking of IL solubilities of $\left[\mathrm{C}_{4} \mathrm{MIM}\right][\mathrm{DBP}]>\left[\mathrm{C}_{4} \mathrm{mim}\right][\mathrm{OAc}]>\left[\mathrm{C}_{4} \mathrm{MIM}\right]\left[\mathrm{HSO}_{4}\right]$ is experimentally observed in different hydrocarbons, which is also in good consistent with the COSMO-RS result (Table S5, Supporting Information). With regard to the effect of hydrocarbon character, the solubilities of the studied ILs in different hydrocarbons generally follow the order of $n$-hexane $<n$-heptane $<n$-octane $<i$-octane $<$ cyclohexane $<$ toluene $<$ benzene. For example, the solubilities of $\left[\mathrm{C}_{4} \mathrm{mim}\right][\mathrm{OAc}]$ in the studied hydrocarbons are in the ranking of $n$-hexane $(-4.026)<n$-heptane $(-4.015)<n$-octane $(-4.003)<i$-octane $(-3.981)<$ cyclohexane $(-3.906)<$ toluene $(-3.193)<$ benzene $(-3.128)$. This ranking agrees well with the effect of hydrocarbon identified by COSMO-RS.

In addition to pure hydrocarbons, the solubility of IL in hydrocarbon mixtures was concerned as well. As a common practice in fuel-related studies, a set of $n$-octane/toluene mixtures with different mass fractions of toluene was prepared as model fuel because alkanes and aromatics are two types of major components in real fuels [10-12]. The solubilities of $\left[\mathrm{C}_{8} \mathrm{mim}\right][\mathrm{OAc}]$ and $\left[\mathrm{C}_{4} \mathrm{mim}\right][\mathrm{DBP}]$ in the hydrocarbon mixtures were then experimentally determined (Fig. 7). As illustrated, both the solubilities of $\left[\mathrm{C}_{8} \mathrm{mim}\right][\mathrm{OAc}]$ and $\left[\mathrm{C}_{4} \mathrm{mim}\right][\mathrm{DBP}]$ in the $n$-octane/toluene mixtures rise gradually with higher toluene mass fraction in the mixture, which can be ascribed to the much higher solubility of ILs in toluene than in $n$-octane. Nevertheless, the solubility of IL in the hydrocarbon mixtures remains in the range between IL-in-octane and IL-in-toluene solubility. These results suggest that the presence of aromatics in real fuels could promote the IL solubility in them to some extent, which is dependent on the aromatic content. The effect of aromatic concentration on the IL 
solubility in hydrocarbon mixtures is also well described by COSMO-RS (Table S7, Supporting Information).

From the above discussion, the COSMO-RS predictions for the effect of IL and hydrocarbon characters were well validated by experiment from the qualitative point of view. Furthermore, the quantitative performance of COSMO-RS was again evaluated by AARD (Table S7, Supporting Information). As seen, the AARD between the experimentally determined IL-in-hydrocarbon solubilities and the corresponding COSMO-RS predictions is 0.3328 , which is higher than that in the validation set (0.1489, in Section 3.1). The larger AARD is mainly owing to the relatively high deviations for the predictions of IL-in-alkane solubility in these cases. Interestingly, it is worth mentioning that if the COSMO-RS predictions are converted by the correlation in Section $3.1(y=1.1318 x+0.3321)$, the AARD is notably reduced to 0.2124 . Such an AARD is comparable to that of the validation set, suggesting that the correlation could be a promising correction for the COSMO-RS predictions of IL-in-hydrocarbon solubility.

\section{Conclusions}

The solubilities of 220 imidazolium-based ILs in 7 model fuel hydrocarbons were systematically studied by COSMO-RS and experiment. It was observed that both cation and anion have a considerable effect on the IL-in-hydrocarbon solubility, which is almost independent of the hydrocarbon character. The effects of IL and hydrocarbon characters on the IL-in-hydrocarbon solubility were reasonably understood by COSMO-RS based molecular interactions. Lower misfit interactions and higher vdW interactions in IL-in-hydrocarbon systems will generally give rise to a larger IL 
solubility, where misfit energies play a more important role than vdW interactions. The experiments with representative ILs validated the satisfactory qualitative and acceptable quantitative performance of COSMO-RS for predicting IL-in-hydrocarbon solubility. Therefore, COSMO-RS is of considerable value to guide the selection of ILs taking account of their potential solubilities in fuel oils for related applications in future research.

\section{Acknowledgements}

This research is supported by the National Sciences Foundation of China (NSFC U1462123), Fundamental Research Funds for the Central Universities of China, and 111 Project (B08021). Zhen Song acknowledges the financial support of China Scholarship Council (CSC) for his joint PhD program No. 201506740031.

\section{Appendix. Supplemental materials}

Supporting Information associated with this work is available via the internet http://www.***. 


\section{References}

[1] J.F. Brennecke, E.J. Maginn, Ionic liquids: innovative fluids for chemical processing, AIChE J. 47 (2001) 2384-2389.

[2] X.P. Zhang, X.C. Zhang, H. Dong, Z. Zhao, S.J. Zhang, Y. Huang, Carbon capture with ionic liquids: overview and progress, Energy Environ. Sci. 5 (2012) $6668-6681$.

[3] Z.G. Lei, C. Dai, J. Zhu, B. Chen, Extractive distillation with ionic liquids: A review, AIChE J. 60 (2014) 3312-3329.

[4] M.A. Martins, U. Domańska, B. Schröder, J.A.P. Coutinho, S.P. Pinho, Selection of Ionic Liquids to be used as Separation Agents for Terpenes and Terpenoids, ACS Sustainable Chem. Eng. 4 (2015) 548-556.

[5] G.W. Meindersma, A.J. Podt, A.B. de Haan, Selection of ionic liquids for the extraction of aromatic hydrocarbons from aromatic/aliphatic mixtures, Fuel Process. Technol. 87 (2005) 59-70.

[6] C. Dai, Y. Dong, J. Han, Z.G. Lei, Separation of benzene and thiophene with a mixture of N-methyl-2-pyrrolidinone (NMP) and ionic liquid as the entrainer, Fluid Phase Equilibr. 388 (2015) 142-150.

[7] M.L. Batista, L.I. Tomé, C.M. Neves, J.R. Gomes, J.A.P. Coutinho, Characterization of systems of thiophene and benzene with ionic liquids, J. Mol. Liq. 192 (2014) 26-31.

[8] J. Han, Z.G. Lei, Y. Dong, C. Dai, B. Chen, Process intensification on the separation of benzene and thiophene by extractive distillation, AIChE J. 61 (2015) 4470-4480.

[9] H. Shekaari, M.T. Zafarani-Moattar, M. Niknam, Thermodynamic evaluation of imidazolium based ionic liquids with thiocyanate anion as effective solvent to thiophene extraction, J. Mol. Liq. 219 (2016) 975-984. 
[10]B. Rodríguez-Cabo, A. Soto, A. Arce, Desulfurization of fuel-oils with $\left[\mathrm{C}_{2} \operatorname{mim}\right]\left[\mathrm{NTf}_{2}\right]$ : a comparative study, J. Chem. Thermodyn. 57 (2013) 248-255.

[11]A. Marciniak, M. Wlazło, Ternary (liquid + liquid) equilibria of \{trifluorotris(perfluoroethyl)phosphate based ionic liquids + thiophene + heptane $\}$ : Part 2, J. Chem. Thermodyn. 86 (2015) 196-201.

[12]A. Ramalingam, A. Balaji, Liquid-liquid equilibrium (LLE) data for ternary mixtures of $\left\{[\mathrm{EMIM}]\left[\mathrm{EtSO}_{4}\right]+\right.$ thiophene/benzothiophene + n-hexadecane $\}$ and $\left\{[\mathrm{EMIM}]\left[\mathrm{MeSO}_{3}\right]+\right.$ thiophene/benzothiophene + n-hexadecane $\}$ at $298.15 \mathrm{~K}, \mathrm{~J}$. Mol. Liq. 212 (2015) 372-381.

[13]A. Kumar, T. Banerjee, Thiophene separation with ionic liquids for desulphurization: a quantum chemical approach, Fluid Phase Equilibr. 278 (2009) $1-8$.

[14]H. Gao, S. Zeng, X. Liu, Y. Nie, X. Zhang, S.J. Zhang, Extractive desulfurization of fuel using N-butylpyridinium-based ionic liquids, RSC Adv. 5 (2015) 30234-30238.

[15]K. Paduszyński, M. Królikowska, Interactions between molecular solutes and task-specific ionic liquid: Measurements of infinite dilution activity coefficients and modeling, J. Mol. Liq. 221 (2016) 235-244.

[16]X. Lu, L. Yue, M. Hu, Q. Cao, L. Xu, Y. Guo, S. Hu, W. Fang, Piperazinium-based ionic liquids with lactate anion for extractive desulfurization of fuels, Energ. Fuel 28 (2014) 1774-1780.

[17]Z. Song, J.J. Zhang, Q. Zeng, H.Y. Cheng, L.F. Chen, Z.W. Qi, Effect of cation alkyl chain length on liquid-liquid equilibria of \{ionic liquids+ thiophene+ heptane \}: COSMO-RS prediction and experimental verification, Fluid Phase Equilibr. 425 (2016) 244-251. 
[18]L.L. Xie, A. Favre-Reguillon, S. Pellet-Rostaing, X.X. Wang, X. Fu, J. Estager, M. Vrinat, M. Lemaire, Selective extraction and identification of neutral nitrogen compounds contained in straight-run diesel feed using chloride based ionic liquid, Ind. Eng. Chem. Res. 47 (2008) 8801-8807.

[19]U. Domańska, M. Królikowski, Phase equilibria study of the binary systems (1-butyl-3-methylimidazolium tosylate ionic liquid + water, or organic solvent), J. Chem. Thermodyn. 42 (2010) 355-362.

[20]U. Domańska, E.V. Lukoshko, M. Królikowski, Phase behaviour of ionic liquid 1-butyl-1-methylpyrrolidinium tris(pentafluoroethyl)trifluorophosphate with alcohols, water and aromatic hydrocarbons, Fluid Phase Equilibr. 345 (2013) $18-22$.

[21]U. Domańska, M. Roguszewska, M. Królikowski, D. Ramjugernath, P. Naidoo, Phase equilibria study of binary systems comprising an (ionic liquid+ hydrocarbon), J. Chem. Thermodyn. 83 (2015) 90-96.

[22]U. Domańska, A. Marciniak, Phase behaviour of 1-hexyloxymethyl-3-methylimidazolium and 1, 3-dihexyloxymethyl-imidazolium based ionic liquids with alcohols, water, ketones and hydrocarbons: the effect of cation and anion on solubility, Fluid Phase Equilibr. 260 (2007) 9-18.

[23]U. Domańska, A. Marciniak, Liquid phase behaviour of 1-hexyloxymethyl-3methyl-imidazolium-based ionic liquids with hydrocarbons: the influence of anion, J. Chem. Thermodyn. 37 (2005) 577-585.

[24]U. Domańska, M. Królikowski, A. Pobudkowska, T.M. Letcher, Phase equilibria study of the binary systems (n-butyl-4-methylpyridinium tosylate ionic liquid + organic solvent, or water), J Chem. Eng. Data 54 (2009) 1435-1441. 
[25]U. Domańska, M. Laskowska, A. Pobudkowska, Phase equilibria study of the binary systems (1-butyl-3-methylimidazolium thiocyanate ionic liquid + organic solvent or water), J. Phys. Chem. B 113 (2009) 6397-6404.

[26]H.T. Shang, J. S. Wu, Q. Zhou, L.S. Wang, Solubilities of benzene, toluene, and xylene isomers in 1-butyl-3-methylimidazolium tetrafluoroborate, J. Chem. Eng. Data 51 (2006) 1286-1288.

[27]M. Bendová, Z. Wagner, Thermodynamic description of liquid-liquid equilibria in systems 1-ethyl-3-methylimidazolium ethylsulfate + C7-hydrocarbons by polymer-solution models, Fluid Phase Equilibr. 284 (2009) 80-85.

[28]M. Blesic, J.N.C. Lopes, M.F.C. Gomes, L.P.N. Rebelo, Solubility of alkanes, alkanols and their fluorinated counterparts in tetraalkylphosphonium ionic liquids, Phys. Chem. Chem. Phys. 12 (2010) 9685-9692.

[29]B. Jiang, L.S. Wang, Solubilities of 1-Hexyl-3-methylimidazole Nitrate and 1-Octyl-3-methylimidazole Nitrate in Selected Solvents, J. Chem. Eng. Data 56 (2011) 4371-4375.

[30]Z. Song, T. Zhou, J. Zhang, H.Y. Cheng, L.F. Chen, Z.W. Qi, Screening of ionic liquids for solvent-sensitive extraction - with deep desulfurization as an example, Chem. Eng. Sci. 129 (2015) 69-77.

[31]S. Gao, G.R. Yu, R. Abro, A. Abdeltawab, S. Al-Deyab, X.C. Chen, Desulfurization of fuel oils: mutual solubility of ionic liquids and fuel oil, Fuel 173 (2016) 164-171.

[32]A. Klamt, F. Eckert, COSMO-RS: a novel and efficient method for the a priori prediction of thermophysical data of liquids, Fluid Phase Equilibr. 172 (2000) 43-72. 
[33]F. Eckert, A. Klamt, Fast solvent screening via quantum chemistry: COSMO-RS approach, AIChE J. 48 (2002) 369-385.

[34]T. Zhou, L. Chen, Y.M. Ye, L.F. Chen, Z.W. Qi, H. Freund, K. Sundmacher, An overview of mutual solubility of ionic liquids and water predicted by COSMO-RS, Ind. Eng. Chem. Res. 51 (2012) 6256-6264.

[35]A.R. Ferreira, M.G. Freire, J.C. Ribeiro, F.M. Lopes, J.G. Crespo, J.A. Coutinho, An overview of the liquid-liquid equilibria of (ionic liquid+ hydrocarbon) binary systems and their modeling by the conductor-like screening model for real solvents, Ind. Eng. Chem. Res. 50 (2011) 5279-5294.

[36]A.R. Ferreira, M.G. Freire, J.C. Ribeiro, F.M. Lopes, J.G. Crespo, J.A. Coutinho, Overview of the liquid-liquid equilibria of ternary systems composed of ionic liquid and aromatic and aliphatic hydrocarbons, and their modeling by COSMO-RS, Ind. Eng. Chem. Res. 51 (2012) 3483-3507.

[37]I. Khan, K.A. Kurnia, F. Mutelet, S.P. Pinho, J.A.P. Coutinho, Probing the interactions between ionic liquids and water: experimental and quantum chemical approach. J. Phys. Chem. B 118 (2014) 1848-1860.

[38]L. Qin, J. Zhang, H.Y. Cheng, L.F. Chen, Z.W. Qi, W.K. Yuan, Selection of imidazolium-based ionic liquids for vitamin E extraction from deodorizer distillate, ACS Sustainable Chem. Eng. 4 (2016) 583-590.

[39] Y. Nie, C. Li, A. Sun, H. Meng, Z. Wang, Extractive desulfurization of gasoline using imidazolium-based phosphoric ionic liquids. Energ. Fuel. 20 (2006) 2083-2087.

[40]H. Gao, C. Guo, J. Xing, J. Zhao, H. Liu, Extraction and oxidative desulfurization of diesel fuel catalyzed by a Brønsted acidic ionic liquid at room temperature. Green Chem. 12 (2010) 1220-1224. 


\section{Figure captions}

Fig. 1 Comparison of COSMO-RS predicted and experimentally determined solubilities of ILs in hydrocarbons. (a) Solubilities of different ILs in hydrocarbons; (b) Solubilities of $\left[\mathrm{C}_{6} \mathrm{mim}\right]\left[\mathrm{NO}_{3}\right]$ in different hydrocarbons.

Fig. 2 COSMO-RS predicted solubilities of 220 imidazolium ILs in (a) $n$-hexane and (b) benzene at $298.15 \mathrm{~K}$.

Fig. 3 COSMO-RS predicted solubilities of $\left[\mathrm{C}_{n} \operatorname{mim}\right][\mathrm{OAc}](\mathrm{n}=1-10)$ in different hydrocarbons.

Fig. 4 Molecular interaction energies of (a) [OAc]-based ILs and (b) [ $\left.\mathrm{C}_{4} \mathrm{mim}\right]$-based ILs with $n$-hexane predicted by COSMO-RS at 298.15 K. (匹) Misfit energies; $(\bullet)$ vdW energies; $(\boldsymbol{\Delta})$ HB energies; $(\bullet) \log _{10}\left(x_{\mathrm{IL}}\right)$.

Fig. 5 Molecular interaction energies of $\left[\mathrm{C}_{4} \mathrm{mim}\right][\mathrm{OAc}]$ with different hydrocarbons predicted by COSMO-RS at 298.15 K. (ロ) Misfit energies; (•) vdW energies; $(\boldsymbol{\Delta})$ HB energies; $(\diamond) \log _{10}\left(x_{\mathrm{IL}}\right)$.

Fig. 6 Experimentally determined solubilities of the studied ILs in different hydrocarbons.

Fig. 7 Experimentally determined solubilities of $\left[\mathrm{C}_{8} \mathrm{mim}\right][\mathrm{OAc}]$ and $\left[\mathrm{C}_{4} \mathrm{mim}\right][\mathrm{DBP}]$ in $n$-octane/toluene mixtures as a function of the toluene mass fraction at 298.15 K. 
Fig. 1. Comparison of COSMO-RS predicted and experimentally determined solubilities of ILs in hydrocarbons. (a) Solubilities of different ILs in hydrocarbons; (b) Solubilities of $\left[\mathrm{C}_{6} \mathrm{mim}\right]\left[\mathrm{NO}_{3}\right]$ in different hydrocarbons.
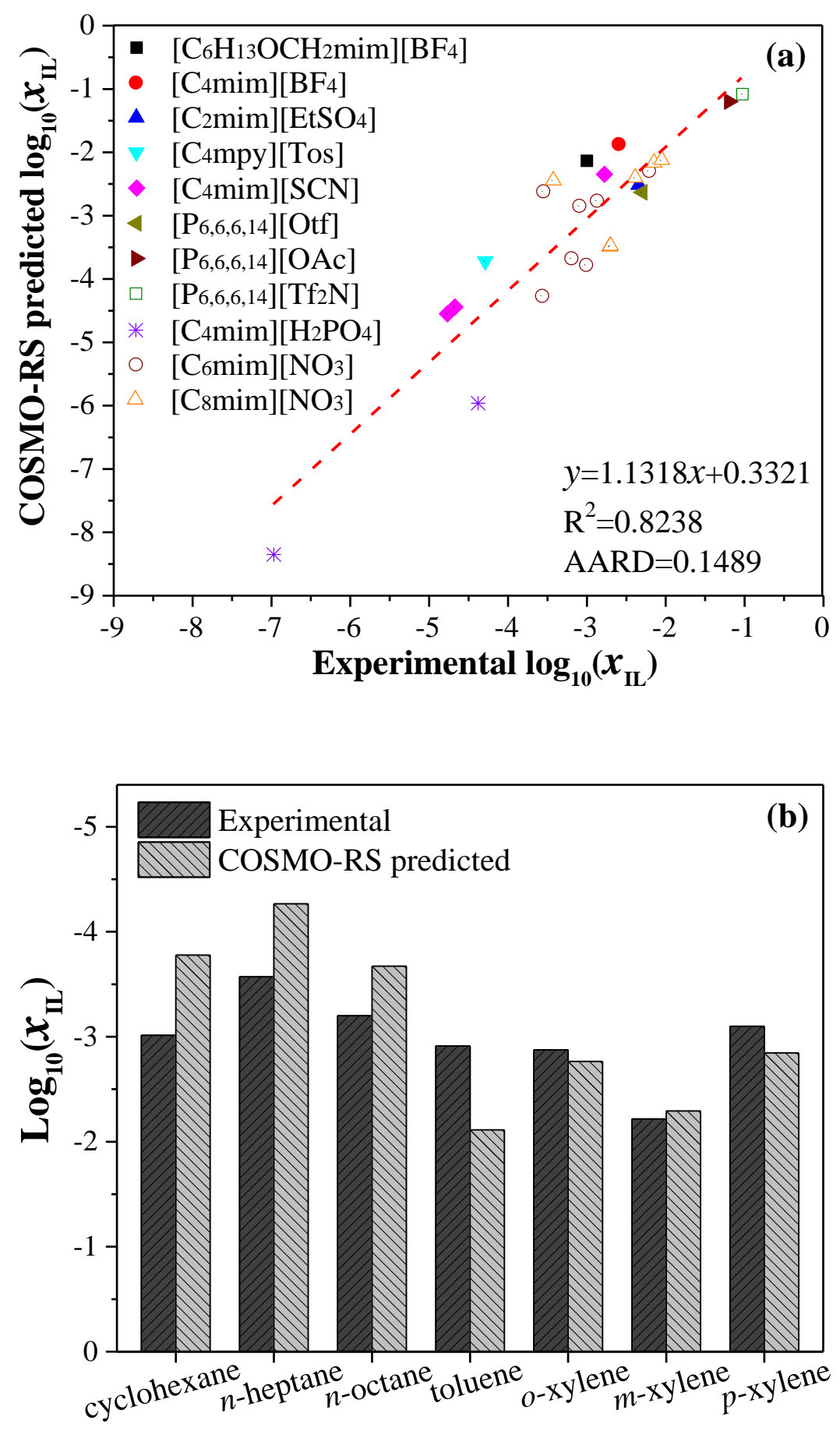
Fig. 2. COSMO-RS predicted solubilities of 220 imidazolium ILs in (a) $n$-hexane and (b) benzene at $298.15 \mathrm{~K}$.

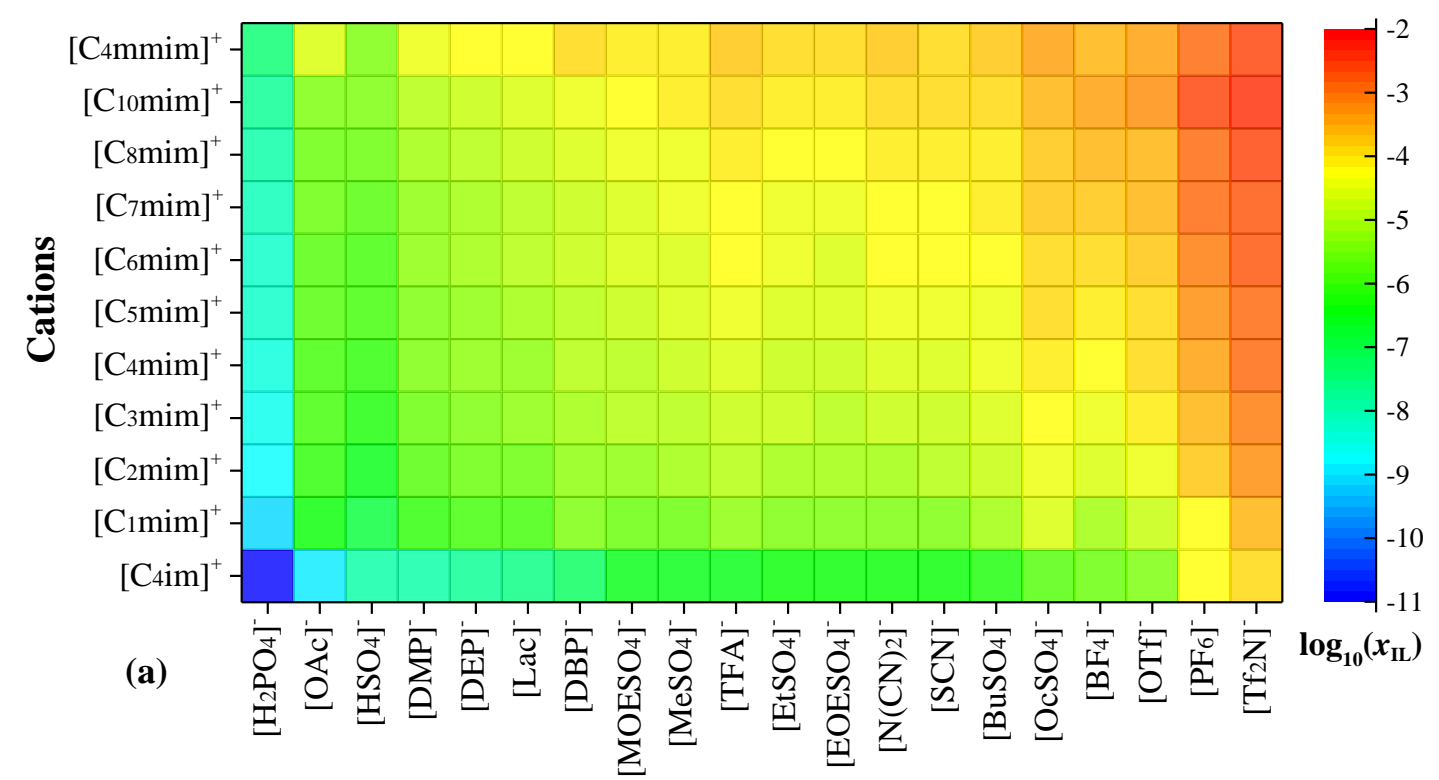

Anions

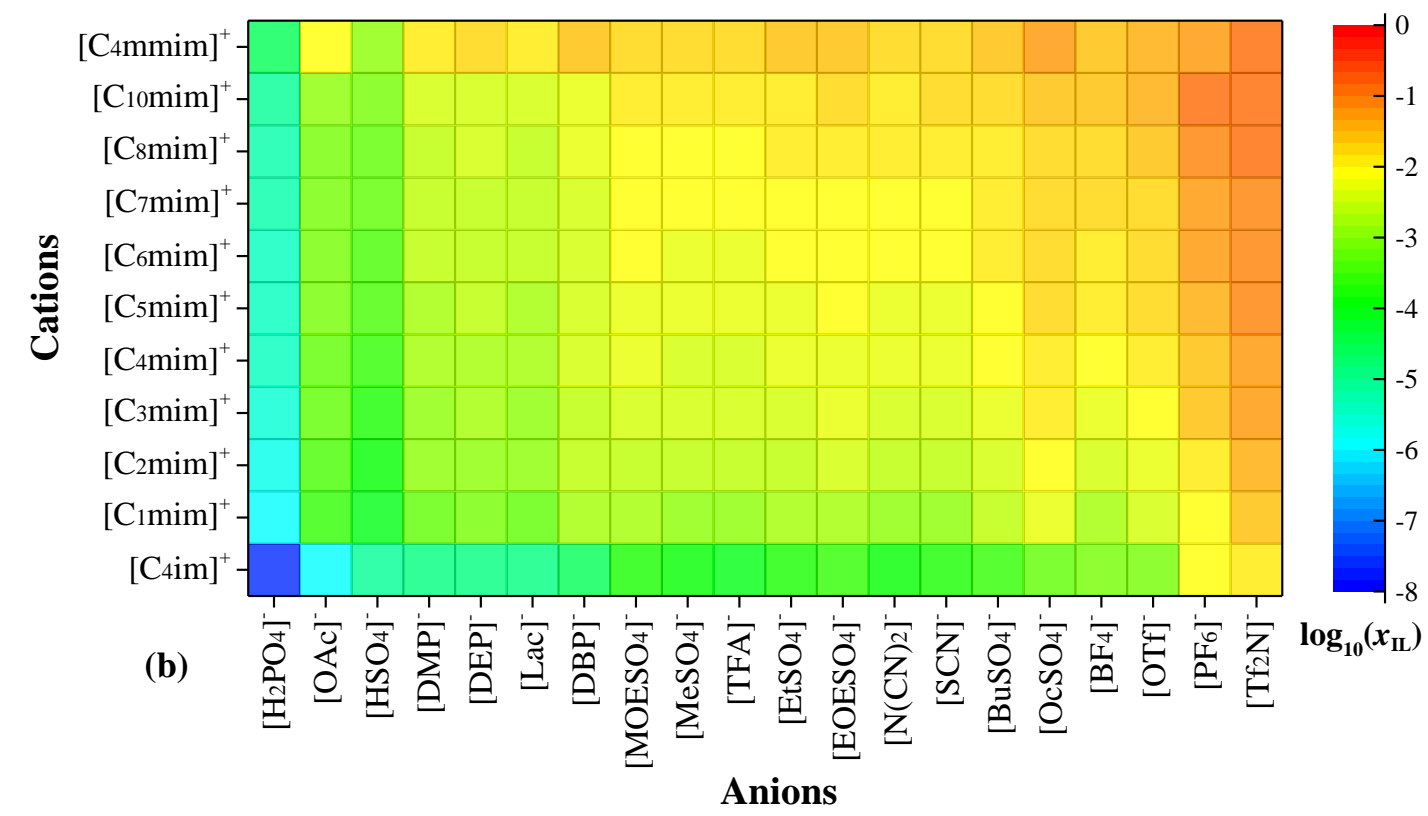


Fig. 3. COSMO-RS predicted solubilities of $\left[\mathrm{C}_{n} \operatorname{mim}\right][\mathrm{OAc}](\mathrm{n}=1-10)$ in different hydrocarbons.

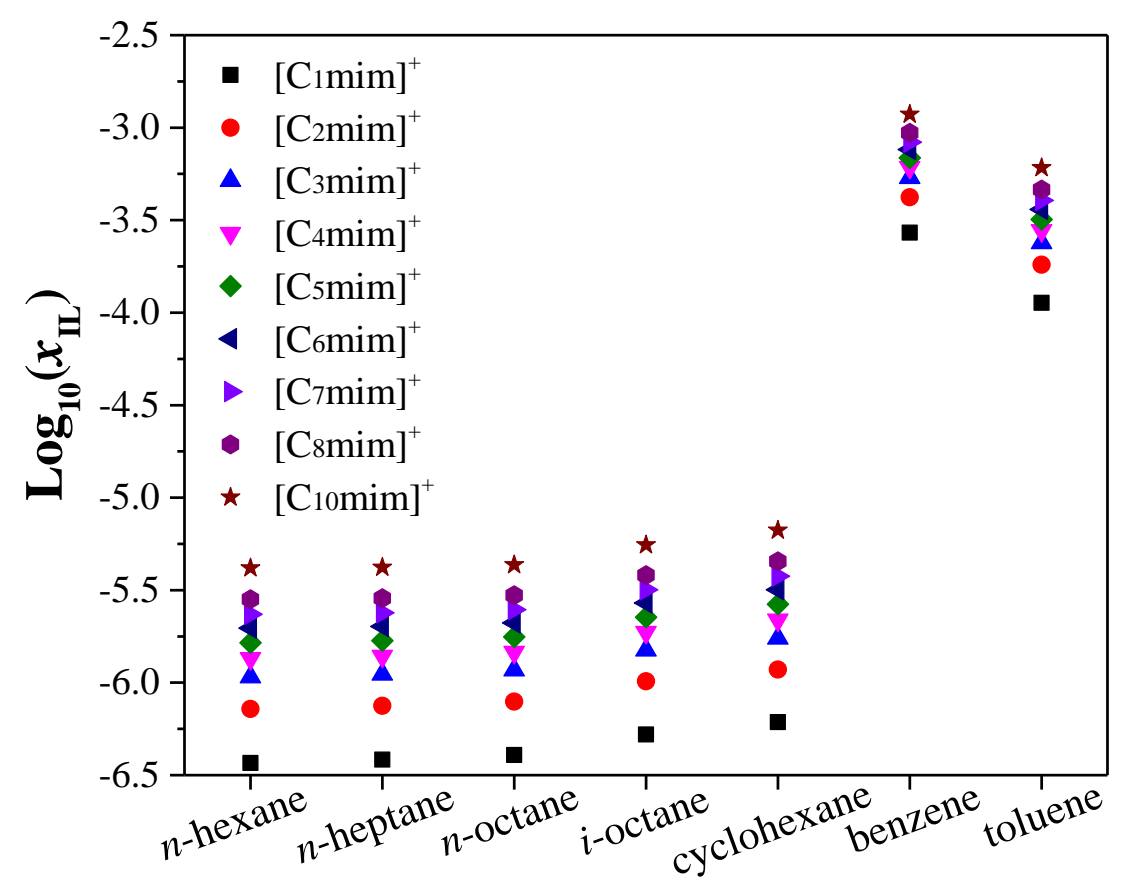


Fig. 4. Molecular interaction energies of (a) [OAc]-based ILs and (b) $\left[\mathrm{C}_{4} \mathrm{mim}\right]$-based ILs with $n$-hexane predicted by COSMO-RS at 298.15 K. (घ) Misfit energies; $(\bullet)$ vdW energies; $(\boldsymbol{\Delta})$ HB energies; $(\bullet) \log _{10}\left(x_{\mathrm{IL}}\right)$.
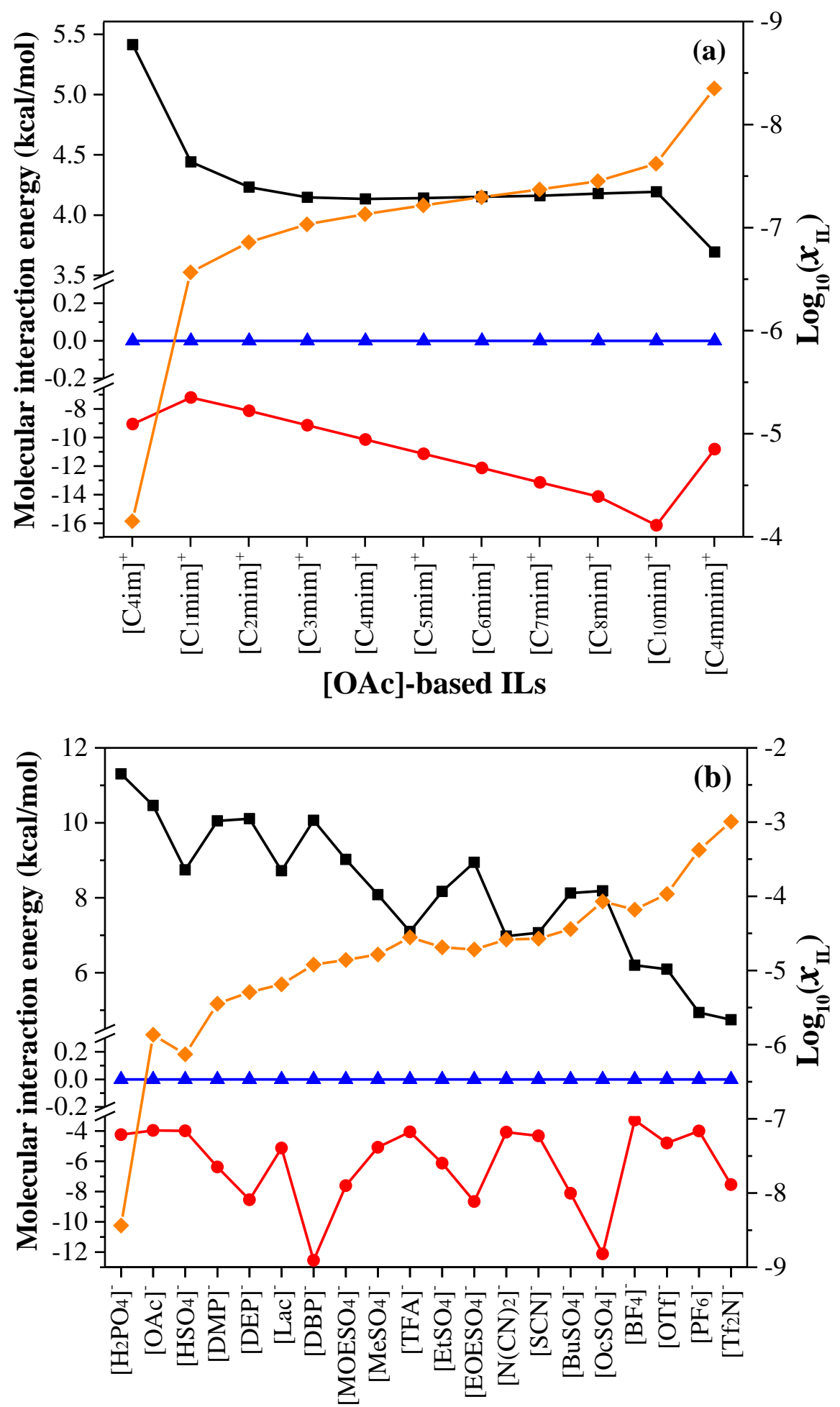

[C4mim]-based ILs 
Fig. 5. Molecular interaction energies of $\left[\mathrm{C}_{4} \mathrm{mim}\right][\mathrm{OAc}]$ with different hydrocarbons predicted by COSMO-RS at 298.15 K. (ロ) Misfit energies; (•) vdW energies; (ム) HB energies; (») $\log _{10}\left(x_{\mathrm{IL}}\right)$.

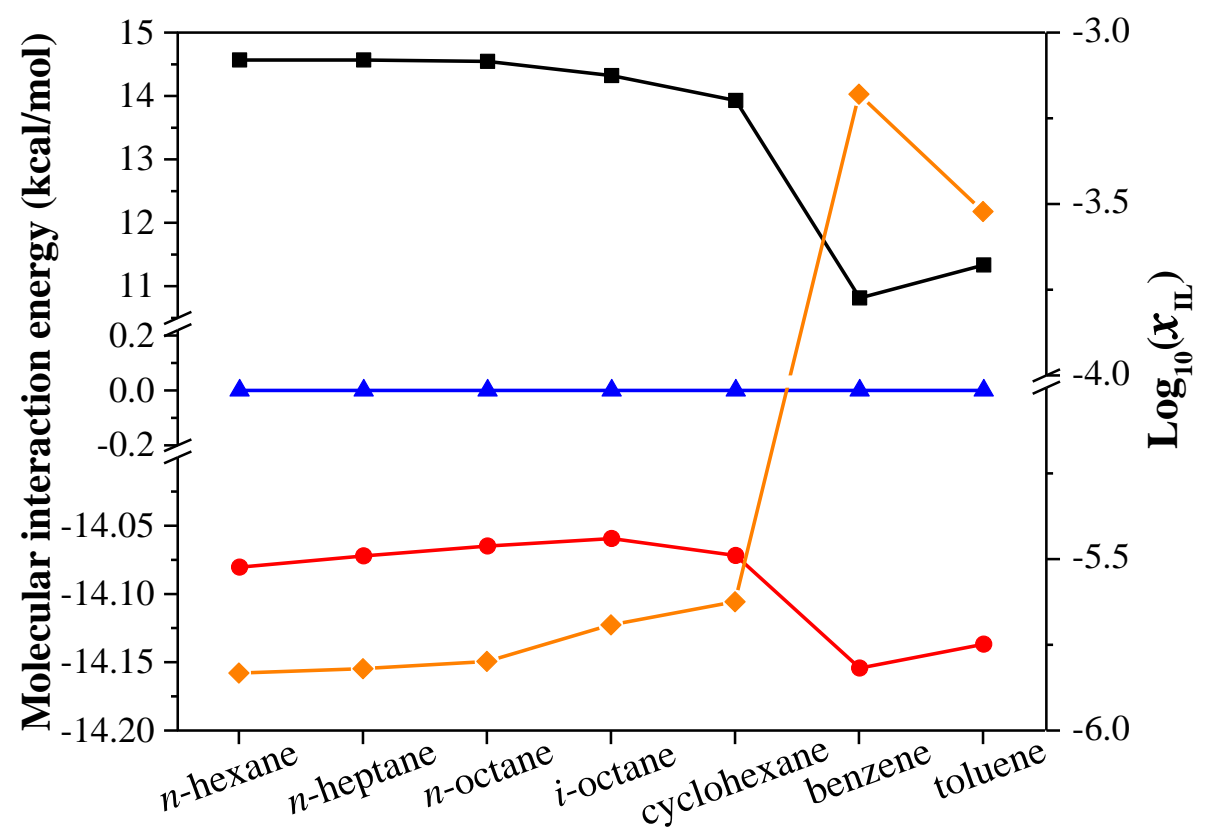


Fig. 6. Experimentally determined solubilities of the studied ILs in different hydrocarbons.

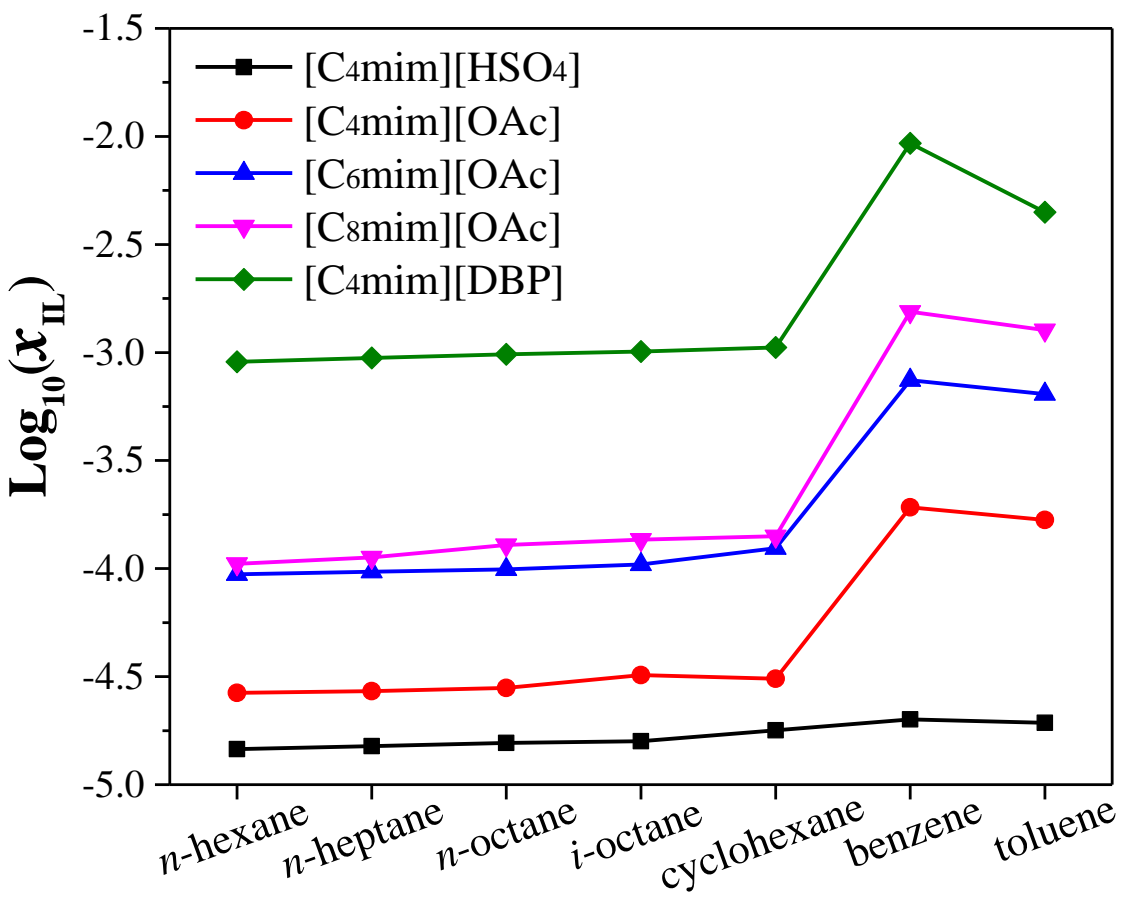


Fig. 7. Experimentally determined solubilities of $\left[\mathrm{C}_{8} \mathrm{mim}\right][\mathrm{OAc}]$ and $\left[\mathrm{C}_{4} \mathrm{mim}\right][\mathrm{DBP}]$ in $n$-octane/toluene mixtures as a function of the toluene mass fraction at 298.15 $\mathrm{K}$.

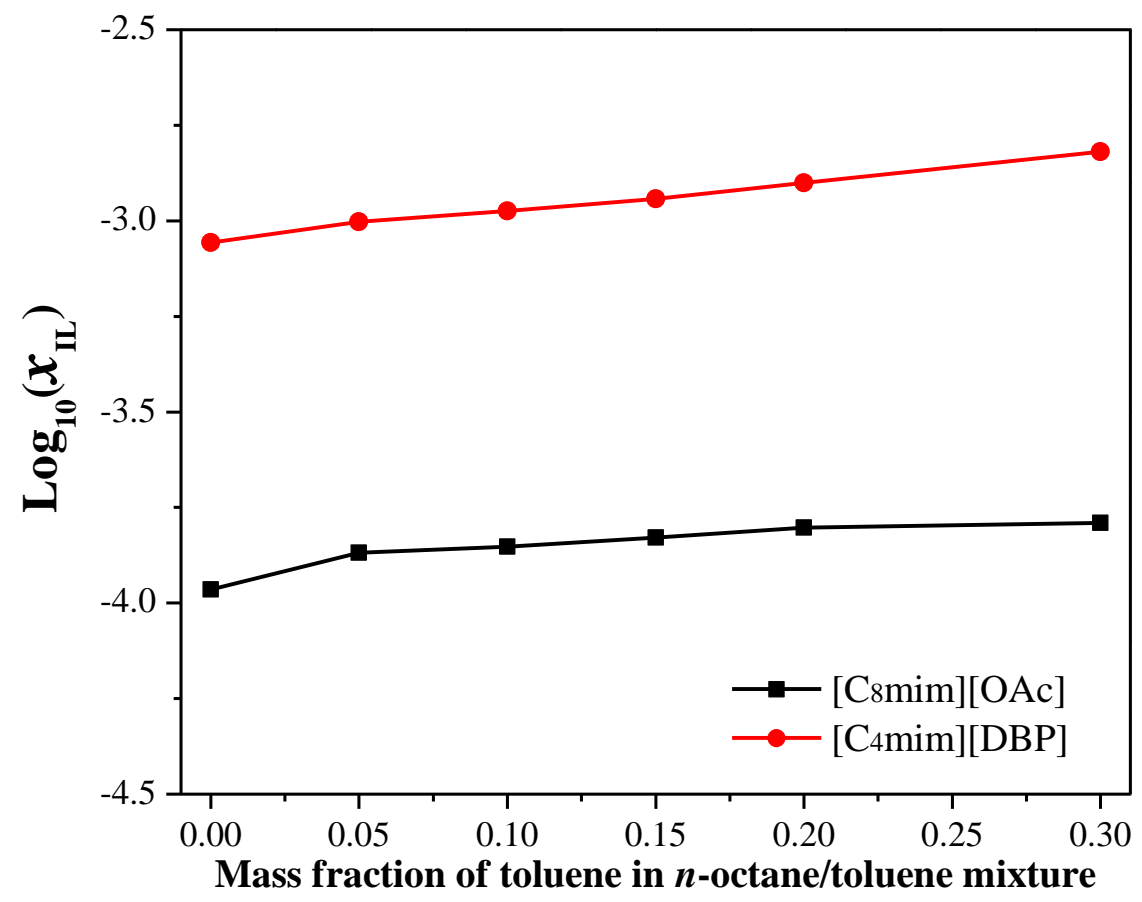




\section{Table 1}

Experimentally determined solubilities of the 5 representative ILs in the studied hydrocarbons at $298.15 \mathrm{~K}$ and atmospheric pressure $\left(\Delta N\right.$-content $\left.(\mathrm{ppm}) / \log _{10} x\right)$.

\begin{tabular}{|c|c|c|c|c|c|}
\hline & {$\left[\mathrm{C}_{4} \mathrm{MIM}\right]\left[\mathrm{HSO}_{4}\right]$} & {$\left[\mathrm{C}_{4} \mathrm{MIM}\right][\mathrm{OAc}]$} & {$\left[\mathrm{C}_{6} \mathrm{MIM}\right][\mathrm{OAc}]$} & {$\left[\mathrm{C}_{8} \mathrm{MIM}\right][\mathrm{OAc}]$} & {$\left[\mathrm{C}_{4} \mathrm{MIM}\right][\mathrm{DBP}]$} \\
\hline$n$-hexane & $3.18 \pm 0.07 /-4.835$ & $5.81 \pm 0.17 /-4.575$ & $20.57 \pm 0.36 /-4.026$ & $22.93 \pm 0.13 /-3.978$ & $197.17 \pm 3.75 /-3.043$ \\
\hline$n$-heptane & $2.88 \pm 0.05 /-4.822$ & $5.18 \pm 0.09 /-4.567$ & $18.46 \pm 0.28 /-4.015$ & $21.53 \pm 0.08 /-3.948$ & $180.15 \pm 4.45 /-3.025$ \\
\hline$n$-octane & $2.69 \pm 0.06 /-4.807$ & $4.84 \pm 0.09 /-4.552$ & $17.13 \pm 0.13 /-4.003$ & $22.19 \pm 0.17 /-3.891$ & $168.88 \pm 0.86 /-3.009$ \\
\hline$i$-octane & $2.69 \pm 0.08 /-4.799$ & $5.45 \pm 0.07 /-4.492$ & $17.69 \pm 0.51 /-3.981$ & $23.03 \pm 0.49 /-3.866$ & $170.83 \pm 1.20 /-2.995$ \\
\hline cyclohexane & $4.63 \pm 0.14 /-4.748$ & $8.01 \pm 0.21 /-4.510$ & $32.20 \pm 0.41 /-3.906$ & $36.66 \pm 0.10 /-3.850$ & $272.83 \pm 5.57 /-2.976$ \\
\hline benzene & $6.33 \pm 0.07 /-4.699$ & $60.59 \pm 1.05 /-3.716$ & $234.3 \pm 5.20 /-3.128$ & $485.63 \pm 4.09 /-2.811$ & $2838.17 \pm 26.35 /-2.032$ \\
\hline toluene & $5.10 \pm 0.11 /-4.713$ & $44.21 \pm 1.30 /-3.775$ & $168.85 \pm 2.67 /-3.192$ & $333.81 \pm 4.17 /-2.896$ & $1160.03 \pm 9.89 /-2.351$ \\
\hline
\end{tabular}

Relative standard uncertainties of $\Delta N$-content are \pm 0.03 , standard uncertainties $\mathrm{u}(\mathrm{T})= \pm 0.1 \mathrm{~K}$. 